\title{
Evaluation of a Model for Predicting the Infection Risk of Squash and Cantaloupe by Pseudoperonospora cubensis
}

Katie N. Neufeld, Center for Integrated Fungal Research, Department of Entomology and Plant Pathology, North Carolina State University, Raleigh, NC 27695; Anthony P. Keinath, Coastal Research and Education Center, Clemson University, Charleston, SC 29634; and Peter S. Ojiambo, ${ }^{\dagger}$ Center for Integrated Fungal Research, Department of Entomology and Plant Pathology, North Carolina State University, Raleigh NC 27695

\begin{abstract}
Infection risk models of downy mildew of cucumber caused by Pseudoperonospora cubensis were evaluated for their performance in predicting the infection risk of squash and cantaloupe plants under field conditions. Experiments were conducted from 2012 to 2014 in Clayton, NC and Charleston, SC, where disease-free potted plants were exposed to weather conditions during a 24- and 48-h period (hereafter 24- and 48-h models, respectively) within a plot with naturally occurring inoculum. Exposed plants were subsequently placed in a growth chamber where they were monitored for disease symptoms, which was indicative of a successful infection. Disease severity was assessed after 7 days as the proportion of leaf area with disease symptoms. Two predictor variables, day temperature and hours of relative humidity $>80 \%$ during each exposure were used as inputs to generate model predictions that were compared with observed data. The threshold probability on the receiver operating characteristic (ROC) curve that minimized the overall error rate for the 24 -h model was 0.85 for both

squash and cantaloupe. The 24-h model was consistently more accurate than the 48-h model in predicting the infection risk for the two hosts. The accuracy of the 24-h model as estimated using area under ROC curve ranged from 0.75 to 0.81 , with a correct classification rate ranging from 0.69 to 0.74 across the two hosts. Specificity rates for the model ranged from 0.81 to 0.84 , while the sensitivity rates ranged from 0.58 to 0.67 . Optimal decisions thresholds $\left(P_{\mathrm{OT}}\right)$ developed based on estimates of economic damage and costs of management showed that $P_{\mathrm{OT}}$ was dependent on the probability of disease occurrence, with the benefit of using the 24-h model for making management decisions being greatest at low levels of probability of disease occurrence. This 24-h model, previously developed using cucumber as the host, resulted in accurate estimates of the daily infection risk of squash and cantaloupe and could potentially be useful when incorporated into a decision support tool to guide fungicide applications to manage downy mildew in these other cucurbit host types.
\end{abstract}

Cucurbit downy mildew (CDM), caused by the obligate oomycete Pseudoperonospora cubensis, is among the most important diseases of cucurbits (Lebeda and Cohen 2011). The pathogen is able to infect a wide range of economically important cucurbit host types, including cucumber (Cucumis sativus), squash (Cucurbita pepo), pumpkin (C. maxima), melon such as cantaloupe and muskmelon (Cucumis melo), and watermelon (Citrullus lanatus) (Lebeda and Widrlechner 2003). The disease occurs globally, where cucurbits are grown in temperate and tropical climatic regions. The pathogen reproduces mainly by asexual production of sporangia and requires its host to reproduce and survive. Although the pathogen is capable of forming oospores under controlled conditions (Thomas et al. 2017), the role of the oospores in the survival of the pathogen in the United States has not been established. Thus, $P$. cubensis is widely thought to overwinter only in areas below approximately $30^{\circ}$ latitude in the United States, where temperatures during winter months are mild and not likely to kill cucurbit host plants (Hausbeck 2017; Holmes et al. 2015). As such, disease epidemics rely on aerial dispersal of sporangia from overwintering sources in the south during periods of strong southerly winds that can transport sporangia over long distances (Ojiambo and Holmes 2011).

Temperature, leaf wetness, and relative humidity (RH) strongly influence infection of cucurbits by $P$. cubensis. Moisture is required

${ }^{\dagger}$ Corresponding author: P. S. Ojiambo; E-mail: pojiamb@ncsu.edu

Funding: Financial support for this work was provided by grants from the United States Department of Agriculture-National Institute of Food and Agriculture (USDA-NIFA) Organic Agriculture Research and Extension Initiative Program Award 2012-51300-20006 and USDA-NIFA Regional Integrated Pest Management Program Awards 2012-34103-19622 and 2012-41530-19623.

Accepted for publication 19 November 2017.

(c) 2018 The American Phytopathological Society for infection and, in its absence, all other weather variables have limited effect on disease development (Palti and Cohen 1980). Once infection occurs, temperature is the dominant factor that determines the rate and extent of infection of cucurbits by P. cubensis (Arauz et al. 2010; Neufeld and Ojiambo 2012). The optimal temperature range for infection is 15 to $22^{\circ} \mathrm{C}$, with at least $2 \mathrm{~h}$ of leaf wetness required for infection to occur (Cohen 1977; Cohen and Rotem 1969; Neufeld and Ojiambo 2012). The interactive effects of temperature and leaf wetness duration have been quantified and the results have been used to develop risk charts for disease development based on host-specific parameters (Neufeld and Ojiambo 2012). This has subsequently enhanced prediction of initial disease outbreaks in the eastern United States using the CDM ipmPIPE forecasting system (Ojiambo et al. 2011). Following the initial fungicide application based the CDM ipmPIPE system, growers typically continue to apply fungicides to their crops on a prophylactic-calendarbased approach, regardless of the subsequent risk of disease development. Such an application of fungicides minimizes the effectiveness of disease control, increases production costs, and has a negative impact on the environment (Pimentel et al. 1992). One approach to maximize the effectiveness of disease control is to use models to guide fungicide applications during the growing season (Madden et al. 2007).

Binary logistic regression models were recently developed to predict the infection risk of cucumber by P. cubensis (Neufeld et al. 2017). These models, based on average day temperature (dT) and hours of $\mathrm{RH}>80 \%$ (RH80) recorded over a $24-$ or 48 -h period, had a good performance on an independent data set. For example, the 24- and 48-h models had correct classification rates $\geq 0.88$ and sensitivity $(S e)$ and specificity $(S p)$ rates $\geq 0.91$ and $\geq 0.71$, respectively, with an overall accuracy $\geq 0.62$ (Neufeld et al. 2017). Optimal decision thresholds needed to reduce costs associated with a single fungicide application and $40 \%$ end-of-season crop loss were also developed. Optimal decision thresholds for CDM on cucumber were found to be dependent on the probability of disease occurrence (i.e., Prev). Further, management decisions informed by the models 
reduced average costs when Prev $\leq 0.50$ and $\leq 0.90$ for the 24 - and 48-h models, respectively. These models provided accurate estimates of the daily infection risk of cucumber by $P$. cubensis and could serve as a useful decision support tool to guide fungicide applications to manage CDM during the growing season. However, the models have not been evaluated for their ability to predict the risk of infection in other cucurbit hosts such as squash and cantaloupe that are also affected by CDM.

Field observations and studies conducted under controlled conditions have shown that cucurbits differentially respond to infection by P. cubensis (Lebeda and Widrlechner 2003; Neufeld and Ojiambo 2012). In general, cucumber is more susceptible to infection by $P$. cubensis than other cucurbit hosts (Neufeld and Ojiambo 2012). In addition, optimum leaf wetness and temperature requirements for infection also vary slightly between hosts. For example, fewer hours of leaf wetness are required to produce the same level of disease intensity on cucumber as compared with squash or cantaloupe (Arauz et al. 2010; Neufeld and Ojiambo 2012). Thus, it is expected that advisory guidelines based on studies conducted on a single cucurbit host (e.g., cucumber) could increase false-positive rates, rendering them less accurate when applied directly to all other cucurbit hosts. Therefore, the models developed to predict the daily infection risk of cucumber by $P$. cubensis need to be validated to establish their usefulness in the management of CDM on other cucurbit hosts.

Although cucurbit hosts types can respond differently to weather factors that influence the development of CDM, it is important to determine whether such differences are large enough to justify the development of host-specific disease prediction models. Typically, growers are less concerned about the risk of disease to a certain crop but rather more concerned about the risk of disease developing in the field regardless of host type (Fabre et al. 2007). Thus, a model that accurately predicts the risk of infection in different cucurbits by $P$. cubensis would be more practical and preferred because it would eliminate extra complexity in the decision-making process (Gent et al. 2013). In addition, because growers tend to be risk averse, there is some uncertainty as to how growers would act on crop-specific disease hazard warnings (Ojiambo et al. 2015). Further, although CDM occurs on cantaloupe, squash, watermelon, and pumpkin, the disease is primarily of economic importance on cantaloupe and squash (Holmes et al. 2015). Costs associated with crop loss may be different in cantaloupe, squash, and cucumber production, and the optimal decision thresholds developed for cucumber (Neufeld et al. 2017) may not be directly applicable to cantaloupe and squash. Thus, this study was carried out with the following objectives: (i) evaluate the performance of the cucumber daily infection risk models on cantaloupe and squash and (ii)

Table 1. Summary of bioassay sets monitored and disease severity attributes for positive sets in bioassay experiments conducted to determine the daily infection risk of squash and cantaloupe by Pseudoperonospora cubensis

\begin{tabular}{|c|c|c|c|c|}
\hline \multirow[b]{2}{*}{ Variable ${ }^{\mathbf{a}}$} & \multicolumn{2}{|c|}{ Squash } & \multicolumn{2}{|c|}{ Cantaloupe } \\
\hline & $\begin{array}{l}\text { 24-h } \\
\text { period }\end{array}$ & $\begin{array}{l}\text { 48-h } \\
\text { period }\end{array}$ & $\begin{array}{l}\text { 24-h } \\
\text { period }\end{array}$ & $\begin{array}{l}\text { 48-h } \\
\text { period }\end{array}$ \\
\hline Total bioassay sets & 124 & 124 & 134 & 134 \\
\hline Positive bioassay sets & 60 & 81 & 77 & 105 \\
\hline Disease prevalence & 0.48 & 0.65 & 0.58 & 0.78 \\
\hline $\begin{array}{l}\text { Maximum disease } \\
\text { severity }(\%)\end{array}$ & 97 & 99 & 86 & 95 \\
\hline $\begin{array}{l}\text { Percent mean disease } \\
\text { severity }^{\mathrm{c}}\end{array}$ & $7.7(1.6)$ & $17.9(2.6)$ & $9.4(1.6)$ & $19.0(2.2)$ \\
\hline Inoculum availability ${ }^{\mathrm{d}}$ & $>1$ spore & $>1$ spore & $>1$ spore & $>1$ spore \\
\hline
\end{tabular}

a A bioassay set was composed of five to eight plants exposed for either 24 or $48 \mathrm{~h}$ to natural inoculum of $P$. cubensis in field plots.

${ }^{b}$ Disease prevalence is the ratio of positive sets to the total number of bioassay sets. The overall disease prevalence across both hosts and exposure periods is 0.62 .

${ }^{c}$ Values in parenthesis are standard errors.

${ }^{\mathrm{d}}$ Sporangia were not counted but simply confirmed to be either present or absent, and at least one sporangium was present during all the exposure periods. derive optimal management action thresholds that reduce average costs of disease control and crop damage in cantaloupe and squash.

\section{Materials and Methods}

Plant material and growth conditions. Plants of the squash cultivar Sunray and cantaloupe cultivar Kermit that are both susceptible to downy mildew were used in the bioassay experiments described below. Seed of these two cultivars were directly sown in 8-cm Styrofoam cups containing vermiculite. After germination, plants (one plant per cup) were maintained in a greenhouse devoid of downy mildew with natural light and a temperature regime of 32 and $26^{\circ} \mathrm{C}$ (day and night, respectively). Plants were watered once every day with deionized water and twice every week with half-strength Hoagland's solution (Hoagland and Arnon 1950).

Squash and cantaloupe field plots were established from 2012 to 2014 at the North Carolina State University Central Crops Research Station in Johnston County, NC, to provide a stable source of natural inoculum for the bioassay experiments. Seed of susceptible straightneck yellow summer squash cultivar Lioness and cantaloupe cultivar Hales Best were directly seeded into raised beds covered with black polythene mulch on 14 May 2012, 29 April 2013, and 19 May 2014. After plants reached maturity and began to senesce, a new set of plants was seeded on 19 July 2012, 5 July 2013, and 4 August 2014. Each experimental plot consisted of 10 rows, about $12 \mathrm{~m}$ long and with $0.5-\mathrm{m}$ spacing between rows. Plots were reseeded 1 week after initial seeding to replace nongerminated seed. Plots were subsequently thinned to one plant per hole 2 weeks after initial seeding. Plants were monitored regularly for growth and, when squash plants reached about 30 days old, fruit was harvested twice a week, while cantaloupe fruit were harvested once a week when plants reached 60 to 70 days old after initial seeding, to maintain plant vigor. Disease within the experimental area was initiated from natural inoculum and disease progress was monitored every 2 weeks to ensure the availability of inoculum during the bioassay experiments. Disease symptoms were first observed on 5 June 2012, 10 June 2013, and 30 June 2014, and disease was allowed to spread throughout the field without any fungicide applications.

Additional field experiments were conducted in parallel at the Clemson University Coastal Research and Education Center in Charleston, SC. These experiments were similar to those established in North Carolina, with the following exceptions. Two sets of field experiments were conducted in 2012 and 2013, while only one experiment was conducted in 2014.

Infection bioassay experiments. A bioassay experiment similar to that described by Royle (1973) and previously used to associate weather factors with plant infection (Neufeld et al. 2017) was used in this study. Briefly, squash and cantaloupe plants raised in the greenhouse were placed in the experimental field plots every week from June to October. Three-week-old plants were placed in the field at $1600 \mathrm{~h}$ and exposed to prevailing weather and natural inoculum for either 24- or 48-h periods to account for the possibility of sporangia deposition occurring on the first day and infection on the second day. In all experiments, bioassay plants were placed between rows in the middle of the plots, approximately 15 to $30 \mathrm{~cm}$ from fully developed squash or cantaloupe plants with visible CDM symptoms. On each exposure period, a single collection of bioassay plants (i.e., bioassay set) consisted of five to eight squash or cantaloupe plants. In total, 124 bioassay sets for squash and 134 bioassay sets for cantaloupe were monitored for the 24- and 48-h exposure periods from 2012 to 2014 (Table 1). Inoculum availability in the field was monitored using a Burkhard volumetric spore trap (Burkhard Manufacturing Co., Rickmansworth, UK) that was located in the lower righthand quadrant of the field about $1 \mathrm{~m}$ from the naturally infected plants. The spore trap was operated continuously each time bioassay plants were exposed in the field. Sporangia were not counted but were simply confirmed as either present or absent during each exposure period. At least one sporangium was present during the entire experimental period.

Following exposure, bioassay plants were placed in a growth chamber with an approximate $\mathrm{RH}$ of $70 \%$ and incubated under a light cycle of $12 \mathrm{~h} /$ day and $12 \mathrm{~h} /$ night and a temperature regime of $22^{\circ} \mathrm{C}$ 
during the day and $18^{\circ} \mathrm{C}$ during the night. Within the growth chamber, plants were watered carefully from the bottom to avoid wetting leaves and reduce the chance of cross-infection during the incubation period. Control (nonexposed) plants were placed in the growth chamber with every set of exposed plants and none of the control plants developed symptoms. At least one exposed plant developed symptoms during experiments and there was no need for a positive control. Individual leaves of the plants were rated 7 days after exposure by estimating the percentage of leaf area infected. To assess leaf area infected, the number and average lesion area was first recorded and leaves were then detached to measure the total leaf area with a portable laser lead area meter (CID Bio-Science, Camas, WA). To determine lesion area, lesion diameter was measured using a rule and then used to estimate lesion area. The mean lesion area from lesions on the first three true leaves was used as an estimate of average lesion area. Disease severity (percentage) was then estimated as (average lesion size/total leaf area) $\times 100$. Mean disease severity across all leaves in each bioassay set (about 15 to 24 leaves) provided an estimate of disease severity for each 24- and 48-h exposure period (Neufeld et al. 2017).

Weather data. Temperature, $\mathrm{RH}$, and solar radiation (SR) at each field site were monitored and recorded every 30 min with a Campbell Scientific CR1000 datalogger (Campbell Scientific, Inc., Logan, UT) and a Watchdog (Spectrum Technologies, Aurora, IL). These instruments were located in the lower righthand quadrant of the field about $1 \mathrm{~m}$ of the naturally inoculated plants. Temperature and $\mathrm{RH}$ were measured $0.5 \mathrm{~m}$ above the ground, whereas SR was measured using a pyranometer that was positioned at ground level. Measurements of temperature and $\mathrm{RH}$ were averaged over each hour. SR dose $\left(\mathrm{MJ} / \mathrm{m}^{-2}\right)$ was calculated using SR and duration of exposure (Kanetis et al. 2010). The predictor variable dT was calculated as the mean temperature when $S R \geq 0.0025 \mathrm{MJ} / \mathrm{m}^{2}$, while the predictor RH80 was calculated as hours when RH was $>80 \%$ over a $24-$ or 48 -h period.

Infection model performance and receiver operating characteristic curve analysis. For each host, bioassay sets for squash and cantaloupe plants from field experiments conducted in North Carolina and South Carolina were combined and analyzed as a single dataset. Bioassay sets for the 24- and 48-h exposure periods were classified as follows: class $=1$ for a bioassay set that was diseased and class $=0$ for bioassay sets that was not diseased. Plants in the bioassay set were deemed to have been diseased when the recorded mean disease severity for a bioassay set was at least $1 \%$. This was the lowest level of severity that could be estimated from bioassay plants that developed disease symptoms. The overall prevalence of disease for the 24-h and 48-h exposure periods was calculated as $P(B+)=B+/ N$, where $B+$ is the number of positive bioassay sets and $N$ is the total number of bioassay sets (Turechek and Wilcox 2005). Recorded weather variables were processed to generate values for dT and RH80 over the 24- and 48-h time period for each bioassay set. Predictions from the 24- and 48-h models based on the recorded weather data were then compared with observations from the bioassay sets. The 24-h model was specified as (Neufeld et al. 2017):

$$
\operatorname{Pr}(Y=1 \mid X)=1 /\{1+\exp [-(-11.5+0.29 \mathrm{RH} 80+0.34 \mathrm{dT})]\}
$$

while the 48-h model was specified as:

$$
\operatorname{Pr}(Y=1 \mid X)=1 /\{1+\exp [-(-9.7+0.13 \mathrm{RH} 80+0.34 \mathrm{dT})]\}
$$

in which $Y=1$ when disease occurs and $X$ is the vector of predictor variables.

Performance of the models based on data collected on squash and cantaloupe was evaluated based on $S e, S p$, accuracy, and the area under the receiver operating characteristic (ROC) curve. $S e$ is the proportion of correctly classified bioassay sets in class $=1$ (plants were diseased), while $S p$ is the proportion of correctly classified bioassay sets in class $=0$ (plants were not diseased). Accuracy of the models was defined as the proportion of correctly classified bioassay sets. The accuracy of the models was also evaluated using the true skill statistic (TSS), defined as TSS $=(S e+S p)-1$. TSS ranges from -1 to +1 , where values of zero or less indicate performance no better than random, while +1 indicates perfect agreement (Allouche et al. 2006). TSS was evaluated as TSS $<0.4=$ low and TSS of 0.40 to $0.55=$ acceptable, 0.55 to $0.70=$ good, 0.70 to $0.85=$ very good, and $>0.85=$ excellent agreement beyond random chance (Monserud and Leemans 1992).

To construct the ROC curve for the 24- and 48-h models, Se (truepositive proportion) was plotted against $1-S p$ (false-positive proportion) for each model and each cucurbit host type. The area under the ROC curve (AUC) was then used to compare the performance of the models. Standard errors of each ROC curve were calculated using PROC LOGISTIC in SAS (version 9.4; SAS Institute, Cary, NC) to test the null hypothesis that the AUC $>0.5$. Models were optimized for a threshold probability $P_{\mathrm{T}}$ that minimizes overall error rate by identifying the point on the ROC curve that is at the furthest distance from the line of no differentiation (Neufeld et al. 2017). This distance is defined as the Youden's index $(J)$ (Metz 1978) and is calculated like TSS as $J=$ $(S e+S p)-1$.

Derivation of optimal decision thresholds. Due to the limitations of the Youden index coupled with the fact that growers tend to be risk averse (Madden et al. 2007; Turechek and Wilcox 2005), an optimum threshold probability $\left(P_{\mathrm{OT}}\right)$ that minimizes management costs relative to errors associated with any recommendation and accounts for the cost of false prediction is necessary to derive optimal decision thresholds (Fabre et al. 2003). For each host type, a cost function was used to derive $P_{\mathrm{OT}}$, as described by Gent and Turechek (2015). Briefly, if $P$ is the probability that a fungicide application will result in a positive net return, $P_{\mathrm{OT}}$ is a threshold value such that, if $P<P_{\mathrm{OT}}$, then a fungicide treatment is not recommended whereas, if $P>P_{\mathrm{OT}}$, then a fungicide treatment is recommended. Following the notation in Neufeld et al. (2017), let $T+$ and $T$-represent a prediction that a treatment is recommended or not recommended, respectively. Further, let bioassay sets where a treatment is required or not required independent of model predictions be denoted by $D+$ and $D$-, respectively, and let the probability of disease outbreak exceeding a given threshold be represented by Prev. Specifically, Prev is the a priori probability of disease outbreak warranting a fungicide application (Gent and Turechek 2015). If the costs $(C)$ associated with $T$ and $D$ are denoted as $C^{++}$(true positive), $C^{+-}$(false positive), $C^{-+}$(false negative), and $C^{--}$(true negative), then the expected costs associated with $P_{\mathrm{OT}}$ [i.e., $C\left(P_{\mathrm{OT}}\right)$ ] for a given probability of disease outbreak can be denoted as:

$$
\begin{aligned}
C\left(P_{\mathrm{OT}}\right)= & \operatorname{Prev}\left[\operatorname{Se} C^{++}+(1-S e) \times C^{-+}\right] \\
& +(1-\operatorname{Prev})\left[\operatorname{Sp} \times C^{--}+(1-S p) \times C^{+-}\right]
\end{aligned}
$$

Thus, equation 3 simply estimates the cost of making an incorrect prediction based on the probability of disease outbreak that warrants a fungicide application. Based upon previous reports, missing up to four sprays in a season can result in yield losses of about 30\% in squash (Fan et al. 2014; Keinath et al. 2014), while missing up to two sprays can result in about $30 \%$ yield loss in cantaloupe (Everts and Newark 2013; Rideout et al. 2007). Thus, costs for $C^{++}$and $C^{+-}$for cantaloupe were estimated to be $\$ 170 /$ ha based on a fungicide application of Omega (active ingredient [a.i.] fluazinam; Syngenta Crop Protection Inc., Greensboro, NC) that costs $\$ 160 /$ ha and an application cost of $\$ 10 /$ ha (Ferreira 2016). Costs for $C^{++}$and $C^{+-}$for squash were estimated to be $\$ 110 /$ ha based on a fungicide application of Zampro (a.i. ametoctradin + dimethomorph; BASF Corporation, Ludwigshafen, Germany) and an application cost of $\$ 10 / \mathrm{ha}$. The cost for $C^{--}$was assumed to be zero for both hosts. The cost of yield loss for cantaloupe was estimated to be $\$ 10,895 / \mathrm{ha}$ based on an average yield of $25,343 \mathrm{~kg} / \mathrm{ha}$ and a price of at $\$ 19.5 /$ cwt (NASS 2012). The cost of yield loss associated with squash was estimated to be $\$ 9,591 / \mathrm{ha}$, based on an average yield of $15,002 \mathrm{~kg} / \mathrm{ha}$ at a national average of $\$ 29 / \mathrm{cwt}$ (NASS 2012).

Optimal decision thresholds were derived as described by Fabre et al. (2007) by minimizing $C\left(P_{\mathrm{OT}}\right)$ over a range of Prev values. This was achieved by setting to zero the first derivative of $C$ with respect to $P_{\mathrm{OT}}$. Approximations of the first derivatives of $S p$ and $S e$ were estimated by fitting data to the following functions (Fabre et al. 2003):

$$
S p\left(P_{\mathrm{OT}}\right)=r p \times \ln \left[k p \times\left(P_{\mathrm{OT}}+1\right)\right]
$$




$$
\left.\operatorname{Se}\left(P_{\mathrm{OT}}\right)=1-k e \times \exp \left[\left(r e \times P_{\mathrm{OT}}\right)-1\right)\right]
$$

First derivatives of equations 4 and 5 were then specified as described by Neufeld et al. (2017) and estimates of the shape parameters $r p$ and $k p$ for curves in equation 4 and parameters $r e$ and $k e$ for the curves in equation 5 were estimated by nonlinear regression using the NLIN procedure in SAS.

\section{Results}

Infection bioassay. The proportion of bioassay sets that were deemed diseased within the 24- or 48-h exposure period during the study period varied among cucurbit hosts (Table 1). Squash plants were diseased in 60 of 124 bioassay sets (48\%) across the entire study for the 24-h exposure periods, with disease severity ranging from 1 to 97\% across the entire experimental period (Fig. 1) and a mean of $7.7 \%$. Cantaloupe plants were infected in 77 of 134 of the bioassay sets $(57 \%)$ for the 24 -h period and had a disease severity range of 1 to $86 \%$ across the entire experimental period (Fig. 1), with a mean of $9.4 \%$ (Table 1). As expected, the number of bioassay sets infected and the corresponding levels of disease severity were higher for the 48-h exposure periods than for the 24-h exposure periods for both hosts (Table 1). For example, the proportion of diseased bioassay sets increased to 65 and $78 \%$, for squash and cantaloupe, respectively, for the 48-h exposure period. The corresponding mean disease severity of 17.8 and $19.0 \%$ for squash and cantaloupe, respectively, was also higher for the 48- than 24-h exposure periods (Table 1). The overall prevalence of the diseases across the entire experimental period was 0.62 .

ROC curve analysis and model performance. The sum of $\mathrm{Se}$ and $S p$ was maximized by a probability cutoff point of 0.85 for the 24-h model for both squash and cantaloupe (Fig. 2A). At this cutoff point, the model had a correct classification rate of 0.74 and accuracy as assessed by AUC of 0.81 for squash (Table 2). The $S e$ and $S p$ rates of the model were 0.67 and 0.81 , respectively, and accuracy based on TSS (=0.48) showed an acceptable model performance (Table 2). For cantaloupe, the 24-h model had a correct classification rate of 0.69 and accuracy as assessed by AUC of 0.75 (Table 2). The $S e$ and $S p$ rates of the model were 0.58 and 0.84 , respectively, while accuracy based on TSS $(=0.42)$ also indicated acceptable model performance (Table 2).
For the 48-h model, the summation of $S e$ and $S p$ was maximized at a probability cutoff of 0.94 and 0.69 for squash and cantaloupe, respectively (Fig. 2B). For both hosts, AUC, correct classification, $S e$, and $S p$ rates for the 48-h model were slightly lower than those for the 24-h model, except for the correct classification and Se rates for cantaloupe (Table 2). For example, model accuracy was low for the 48-h model, with AUC values of 0.79 and 0.68 for squash and cantaloupe, respectively (Table 2 ). The TSS value of the 48-h model for squash $(\mathrm{TSS}=0.38)$ and cantaloupe $(\mathrm{TSS}=0.28)$ indicated a low level of model performance (Table 2).

Optimal decision thresholds. For both hosts, nonlinear regression of $P_{\mathrm{OT}}$ on $S p$ (equation 2) or $S e$ (equation 3) provided a good fit to the observed $S p$ and $S e$ values, respectively, for the 24- and 48-h models (Fig. 3). Estimates of the parameters describing the shape of the $S e$ and $S p$ curves were all significantly $(P<0.05)$ different from zero and well estimated. Estimates for the $S p$ curves for the 24- and 48-h models were generally more similar than the estimates for the Se curves for the two models (Table 3). For squash and cantaloupe, $P_{\mathrm{OT}}$ decreased with increasing Prev, with the decrease being much steeper for the 24-h model than for the 48-h model (Fig. 4). In addition, the decrease in $P_{\mathrm{OT}}$ with increasing Prev was more pronounced for cantaloupe than for squash with both models. Model predictions reduced average costs compared with routine fungicide application in squash and cantaloupe, with actual reductions being dependent on Prev. For a $30 \%$ end-of-season yield loss in squash, predictions based on the 24 - and 48-h models reduced average fungicide costs compared with routine application for Prev $<0.80$ and 1.0, respectively (Fig. 4A). Assuming a $30 \%$ yield loss in cantaloupe, the 24- and 48-h models predictions reduced average fungicide costs compared to routine application for Prev $<0.60$ and 0.80 , respectively (Fig. 4B).

\section{Discussion}

This study was conducted to evaluate the performance of models recently developed to predict the daily infection risk of cucurbits by $P$. cubensis. These models were originally developed using cucumber as the host for which dT and RH80 were the best predictor variables for the risk of infection. Our results show that models developed for cucumber successfully predicted the risk of infection
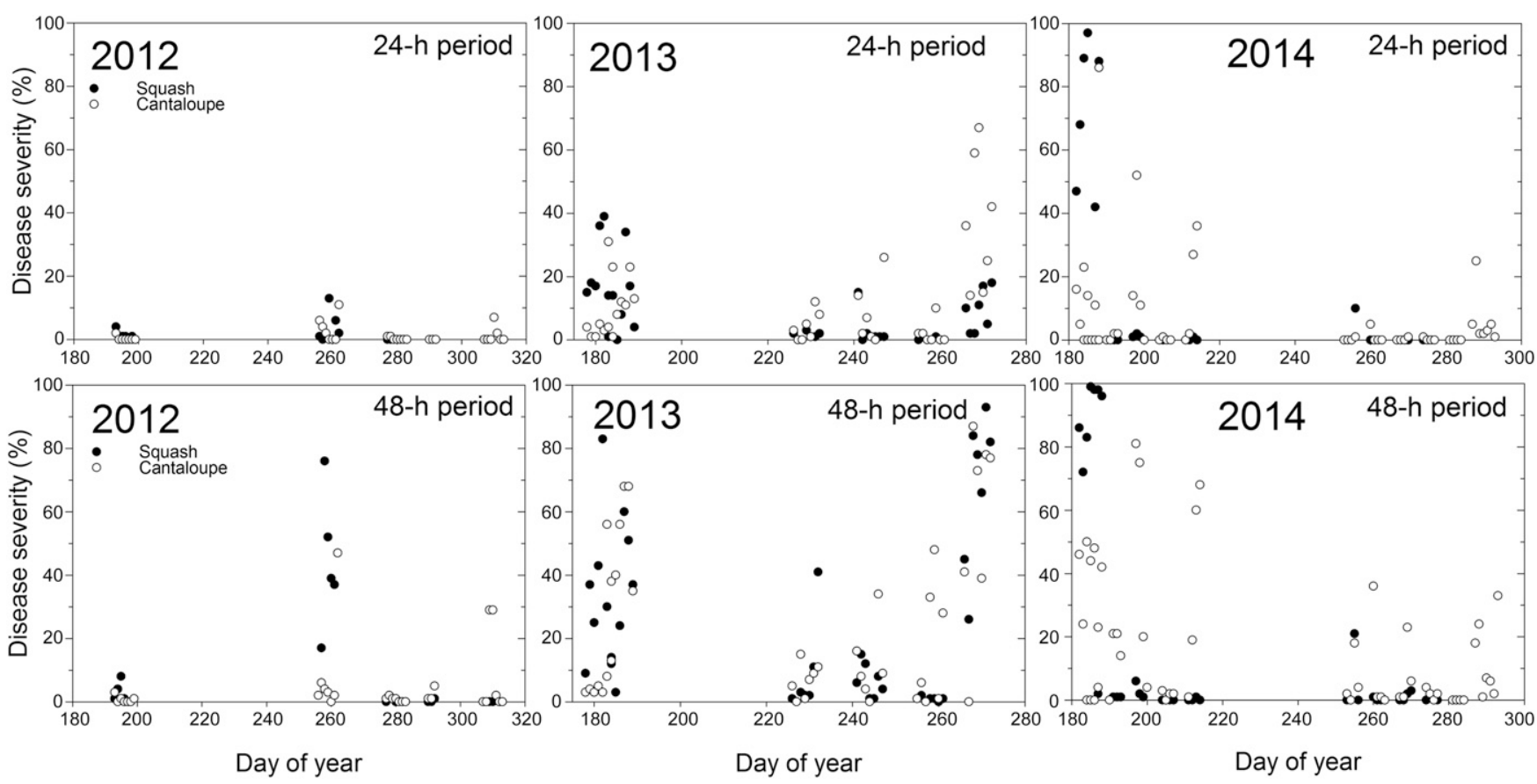

Fig. 1. Severity of downy mildew on squash and cantaloupe plants in bioassay field experiments conducted in North Carolina and South Carolina from 2012 to 2014 to evaluate the performance of day temperature and hours of relative humidity $>80 \%$ as useful predictors of risk of infection. Values shown are means of leaf area infected (\%) from a bioassay set composed of five to eight plants. 
in squash and cantaloupe and, specifically, the 24-h model had a comparatively high level of accuracy, with all other test statistics indicating a good performance in predicting risk of infection in squash and cantaloupe. Further, optimal decision thresholds that could reduce average management costs were established based on specific economic assumptions and our results showed that the models had the greatest value in guiding management decisions when the probability of disease outbreak was relatively low in both squash and cantaloupe. Thus, these models are expected to better guide management decisions on fungicide sprays to control CDM during the growing season.

Temperature and moisture affect sporangia germination and infection of cucurbits by P. cubensis (Cohen and Rotem 1969). Hours of RH above a certain threshold (e.g., RH80), have also been found to be useful indicators of moisture (Rowlandson et al. 2015; Sentelhas

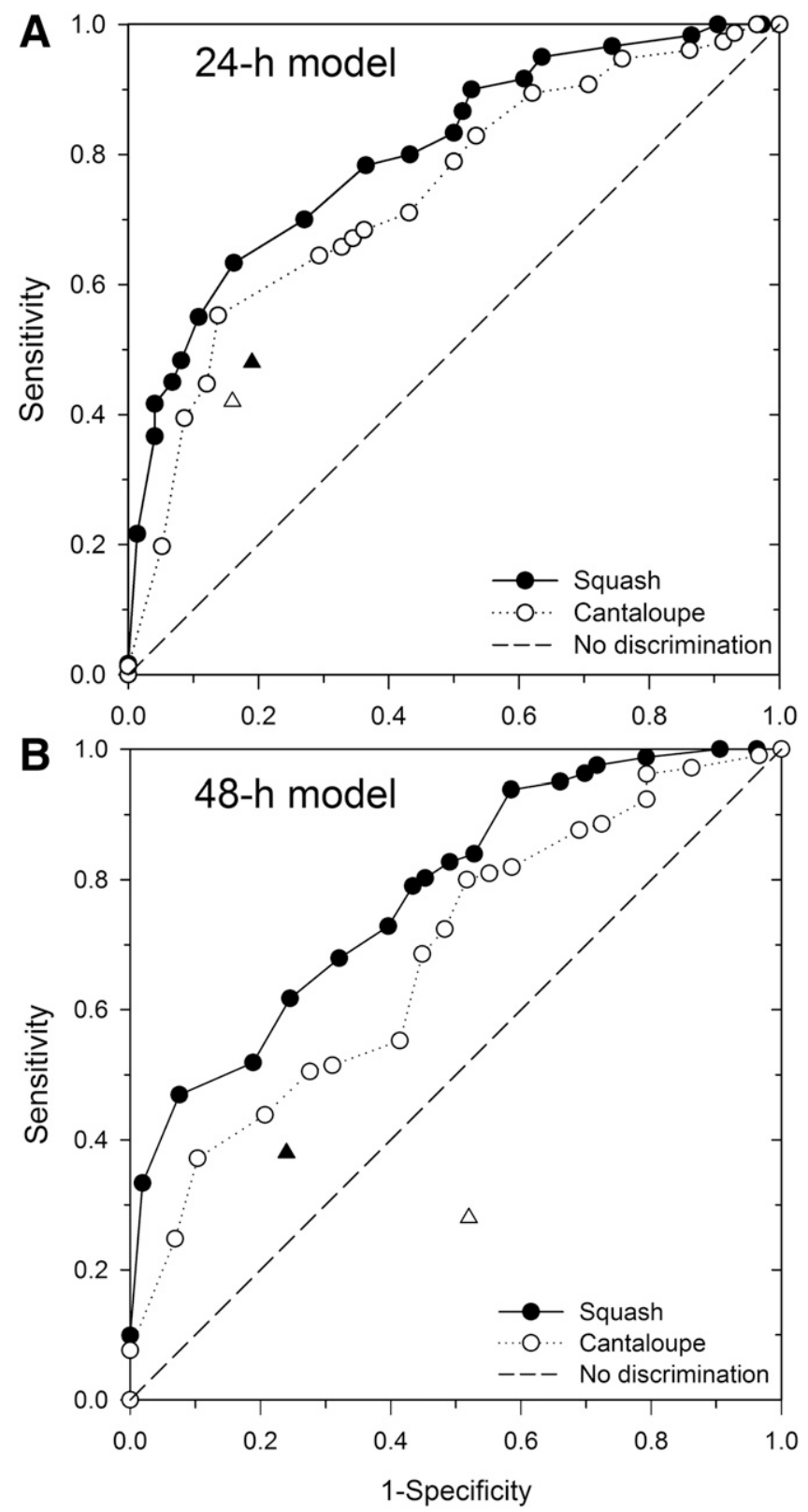

Fig. 2. Receiver operating characteristic curves for the A, 24-h and B, 48-h models evaluated to predict the daily infection risk of cantaloupe and squash by Pseudoperonospora cubensis. Solid or open circles represent select action thresholds or cutoff points that can be used to classify observations. Solid and open triangles are values of the Youden's index for squash and cantaloupe, respectively. The dashed line is a reference line that represents no discrimination for a model that predicts infection no better than chance. et al. 2008). Measurements of temperature and moisture (or duration of RH) have also been found to be useful predictors of the risk of infection in hop by P. humili (Gent and Ocamb 2009; Royle 1973). In general, cucumber is more susceptible to CDM than squash or cantaloupe (Arauz et al. 2010; Neufeld and Ojiambo 2012). Further, while the optimum range of temperature required for infection is similar across cucurbits, infection of specific hosts by $P$. cubensis is largely dependent on the interactive effects of temperature and duration of leaf wetness (Neufeld and Ojiambo 2012). For example, at $20^{\circ} \mathrm{C}$, $15 \%$ disease severity was expected following 2,4 , and $8 \mathrm{~h}$ of wetness for cucumber, squash, and cantaloupe, respectively (Neufeld and Ojiambo 2012). When temperature increases to $25^{\circ} \mathrm{C}$, a disease severity of $15 \%$ is expected following 3,7 , and $15 \mathrm{~h}$ of wetness for cucumber, squash, and cantaloupe, respectively. The effect of cucurbit host type on infection is characterized primarily by differences in the response of the upper limit of infection to temperature rather than whether infection occurs or not (Neufeld and Ojiambo 2012). Thus, models developed to predict the daily infection risk for cucumber are expected to perform reasonably well when used to predict the infection risk of squash or cantaloupe by $P$. cubensis. In this study, the accuracy of the 24 -h model was 0.81 for squash and 0.75 for cantaloupe compared with 0.86 for cucumber (Neufeld et al. 2017). Model accuracy based on the 48-h bioassay sets was 0.79 and 0.68 for squash and cantaloupe, respectively, compared with 0.82 for cucumber. Model accuracy based on TSS indicated that the 24-h model had an acceptable performance for squash compared with good performance for cucumber. However, growers tend to be risk averse and cropspecific disease hazard warnings are unlikely to be acted upon (Madden et al. 2007; Ojiambo et al. 2015). Thus, although small differences exists in the performance of these models on different cucurbits, the models previously developed on the more susceptible cucumber should be able to provide accurate risk of the daily infection risk across important cucurbit hosts.

Several decision support systems have been developed to guide fungicide applications to control diseases in different crops (Gent et al. 2013). The probability that growers will adopt such systems is likely to be high if these decision tools offer a cost advantage over calendar-based approaches. Although cantaloupe has a higher value than squash and cucumber (NASS 2012), cucurbits are a low-value crop compared with solanaceous vegetable crops with similar disease management costs. Thus, cucurbit growers are interested in making decisions that minimize the average management costs associated with CDM. In this study, optimal economic decision thresholds were dependent on the probability of disease occurrence (i.e., Prev), with

Table 2. Performance characteristics of the final binary logistic regression models developed to predict the probability of infection of squash and cantaloupe by Pseudoperonospora cubensis

\begin{tabular}{lccccc}
\hline & \multicolumn{2}{c}{ Squash } & & \multicolumn{2}{c}{ Cantaloupe } \\
\cline { 2 - 3 } \cline { 5 - 6 } Test statistic & 24-h model & 48-h model & & 24-h model & 48-h model \\
\hline AUC $^{\text {a }}$ & 0.81 & 0.79 & & 0.75 & 0.68 \\
Correct classification $^{\mathrm{b}}$ & 0.74 & 0.67 & & 0.69 & 0.73 \\
Sensitivityc $^{\mathrm{c}}$ & 0.67 & 0.62 & & 0.58 & 0.80 \\
Specificity $^{\mathrm{d}}$ & 0.81 & 0.76 & & 0.84 & 0.48 \\
TSS $^{\mathrm{e}}$ & 0.48 & 0.38 & & 0.42 & 0.28 \\
\hline
\end{tabular}

a Area under receiver operating curve (AUC) is a ranking-based measure of classification performance and provides a threshold-independent measure of the prediction accuracy of a model; values closer to 1 indicate a high overall accuracy.

${ }^{\mathrm{b}}$ Correct classification is the proportion of correctly classified bioassay sets within the dataset.

${ }^{\mathrm{c}}$ Sensitivity is the proportion of correctly classified bioassay sets in class $=1$ (i.e., when infection occurred).

${ }^{\mathrm{d}}$ Specificity is the proportion of correctly classified bioassay sets in class $=$ 0 (i.e., when infection did not occur).

e True skill statistic (TSS) is a synthetic index that takes into account sensitivity and specificity, and ranges from -1 to +1 , where values of zero or less indicate a performance no better than random and +1 indicates perfect agreement. 
economic decision thresholds being most effective when the probability was low. This observation was consistent with that reported for cucumber (Neufeld et al. 2017) and other crops (Fabre et al. 2003; Gent and Ocamb 2009; Fabre et al. 2003). The cost associated with an unnecessary fungicide application is expected to be much greater than the economic cost of crop loss when the probability of disease occurrence in either squash, cantaloupe, or cucumber is low. In the eastern United States, growers tend to spray their crops at the first sign of symptoms when conditions are dry and warm during late spring and early summer, which are likely to result in a relatively low probability of disease occurrence. In this case, these models could help growers decide whether continued fungicide applications are necessary during this period. It is important to note that there is both an upper limit where routine sprays will always be less costly and a lower limit where never spraying will be less costly as compared with using a model with a given error rate. For example, for an assumed Prev $=0.15$, the probability threshold for squash and cantaloupe would be 0.57 and 0.49 , respectively, for the $24-h$ model. Increasing the probability of disease occurrence to Prev = 0.3 decreases the probability threshold for squash and cantaloupe to 0.41 and 0.29 , respectively.

As with cucumber, for low values of $P_{\mathrm{OT}}, S e$ decreased slowly but $S p$ increased more rapidly with increasing $P_{\mathrm{OT}}$. This suggests that any misclassified bioassay sets may have been due to variability in infection by $P$. cubensis as a result of spatial heterogeneity in the inoculum in the field (Neufeld et al. 2013). Although CDM occurs annually in the eastern United States (Ojiambo et al. 2015), the timing of sporangia transport from infected source fields still remains the
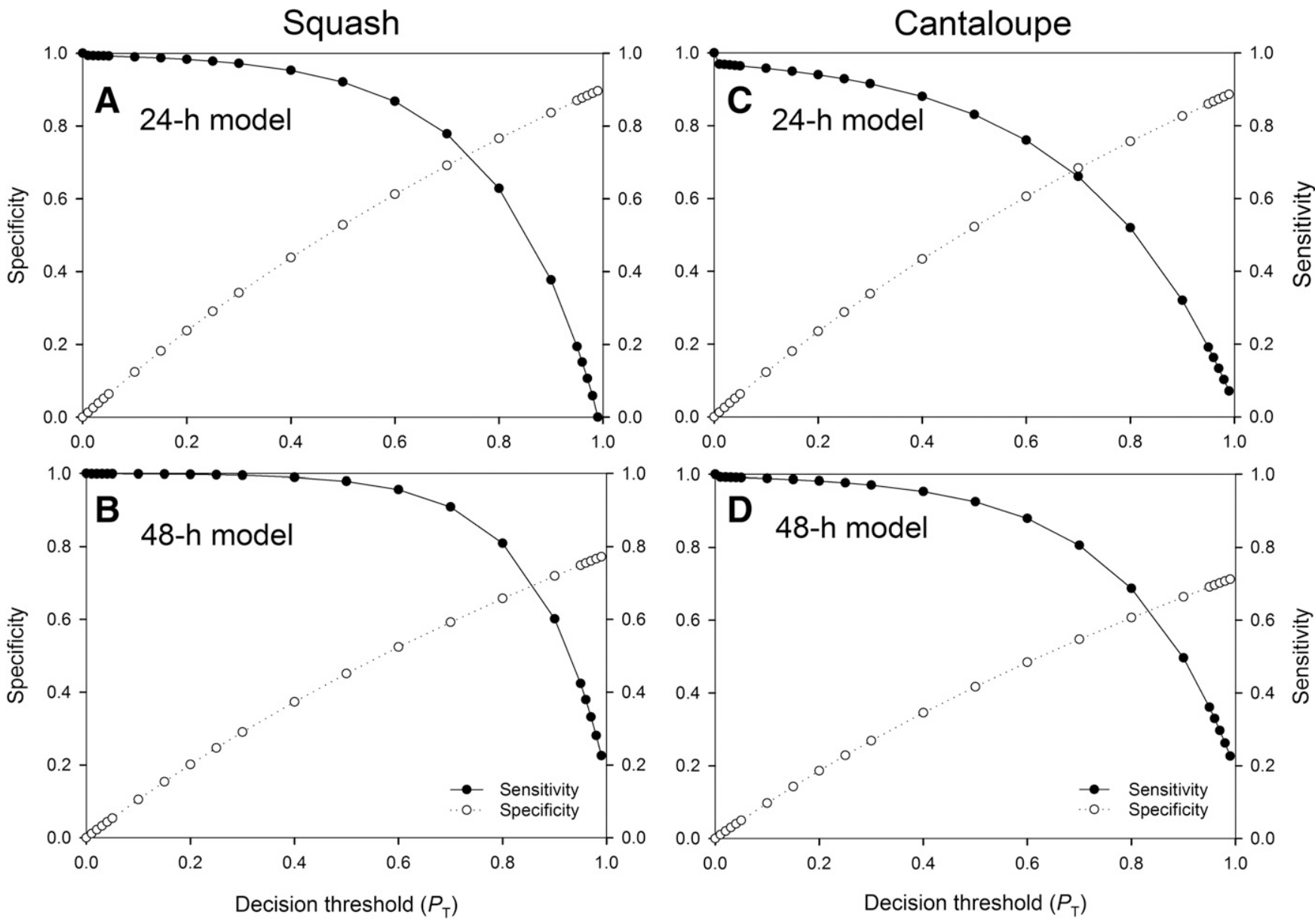

Fig. 3. Observed (circles) and modeled (lines) sensitivity and specificity values from nonlinear regression models for the A and C, 24-h and B and D, 48-h models as a function of each potential optimum decision threshold $\left(P_{\mathrm{OT}}\right)$ for squash $(\mathrm{A}$ and $\mathrm{B})$ and cantaloupe $(\mathrm{C}$ and $\mathrm{D})$. Solid or open circles represent select action thresholds or cutoff points that can be used to classify observations. Here, $P_{\mathrm{OT}}$ is a threshold value such that, if $P<P_{\mathrm{OT}}$, then a fungicide treatment is not recommended, whereas if $P>P_{\mathrm{OT}}$, then a fungicide treatment is recommended. In this case, $P$ is the probability that a fungicide treatment will provide a positive net return.

Table 3. Estimates of the shape parameters used to describe the sensitivity and specificity of logistic regression models in classifying the favorability of a 24 - or 48-h period in the infection of squash and cantaloupe by Pseudoperonospora cubensis

\begin{tabular}{|c|c|c|c|c|c|c|c|c|c|}
\hline \multirow[b]{3}{*}{ Host } & \multirow[b]{3}{*}{ Model } & \multicolumn{8}{|c|}{ Shape parameter ${ }^{a}$} \\
\hline & & \multicolumn{2}{|c|}{$r p$} & \multicolumn{2}{|c|}{$k p$} & \multicolumn{2}{|c|}{$r e$} & \multicolumn{2}{|c|}{ ke } \\
\hline & & Estimate & S.E. & Estimate & S.E. & Estimate & S.E. & Estimate & S.E. \\
\hline \multirow[t]{2}{*}{$\overline{\text { Squash }}$} & 24-h & 1.300 & 0.030 & 1.003 & 0.010 & 5.165 & 0.199 & 0.016 & 0.003 \\
\hline & 48-h & 1.204 & 0.042 & 0.908 & 0.011 & 7.383 & 0.294 & 0.001 & 0.0004 \\
\hline \multirow[t]{2}{*}{ Cantaloupe } & 24-h & 1.278 & 0.032 & 1.010 & 0.011 & 3.475 & 0.125 & 0.081 & 0.009 \\
\hline & 48-h & 1.095 & 0.044 & 0.927 & 0.014 & 4.771 & 0.145 & 0.019 & 0.002 \\
\hline
\end{tabular}

a Parameters $r p$ and $k p$ describe the parametric form of the specificity curve, while $r e$ and $k e$ describe the parametric for the sensitivity curve. S.E. is the standard error of the parameter estimate. 
most uncertain feature within the prediction framework of CDM (Ojiambo and Holmes 2011; Ojiambo and Kang 2013). Thus, accounting for heterogeneity in sporangia availability in local or neighboring fields (Granke et al. 2014) could further improve the accuracy of these models in predicting the daily infection of cucurbits by P. cubensis.

The 24-h model consistently had high levels of accuracy and performance compared with the 48-h model for squash, cantaloupe, and cucumber. Thus, the 24 -h model should be preferred over the 48 -h model to guide decisions on fungicide applications to control $\mathrm{CDM}$ during the growing season. In other studies, the infection risk of hop was equally predicted by the 24- and 48-h model, with both models having a correct classification rate of 0.86 (Gent and Ocamb 2009). However, in the study by Gent and Ocamb (2009), the increase in the number of positive bioassay sets between the 24- and 48-h exposure period was negligible. In the present study, the number of positive bioassay sets between the two exposure periods increased by about $35 \%$ across the two cucurbit hosts. Thus, this rapid increase in the number of positive bioassay sets in a relatively short period of time may have reduced the predictive accuracy of the 48-h model.
Optimal decision thresholds developed using predictions from the 24- and 48-h models were based on economic assumptions used in this study. The production situation of each specific field, including physical, biological, and socioeconomic factors that determine agricultural production, can greatly affect the effectiveness of model prediction in guiding decisions associated with management of the disease. Thus, differences in management costs for fungicides and costs associated with yield loss and fungicide application may influence optimum decisions thresholds established in this study. In addition, studies need to be conducted to determine the utility of these models in guiding fungicide applications during the growing season in comparison with prophylactic calendar-based fungicide applications. Such studies should provide data to establish the cost effectiveness of the timings of fungicide applications based on model predictions compared with calendar-based applications to CDM during the growing season.

In summary, the 24-h prediction model validated in the present study could be used in tandem with the CDM ipmPIPE forecasting system for the overall management of CDM in the eastern United States. The CDM ipmPIPE forecasting system is an online system that predicts the initial infection and, thus, the need for the first
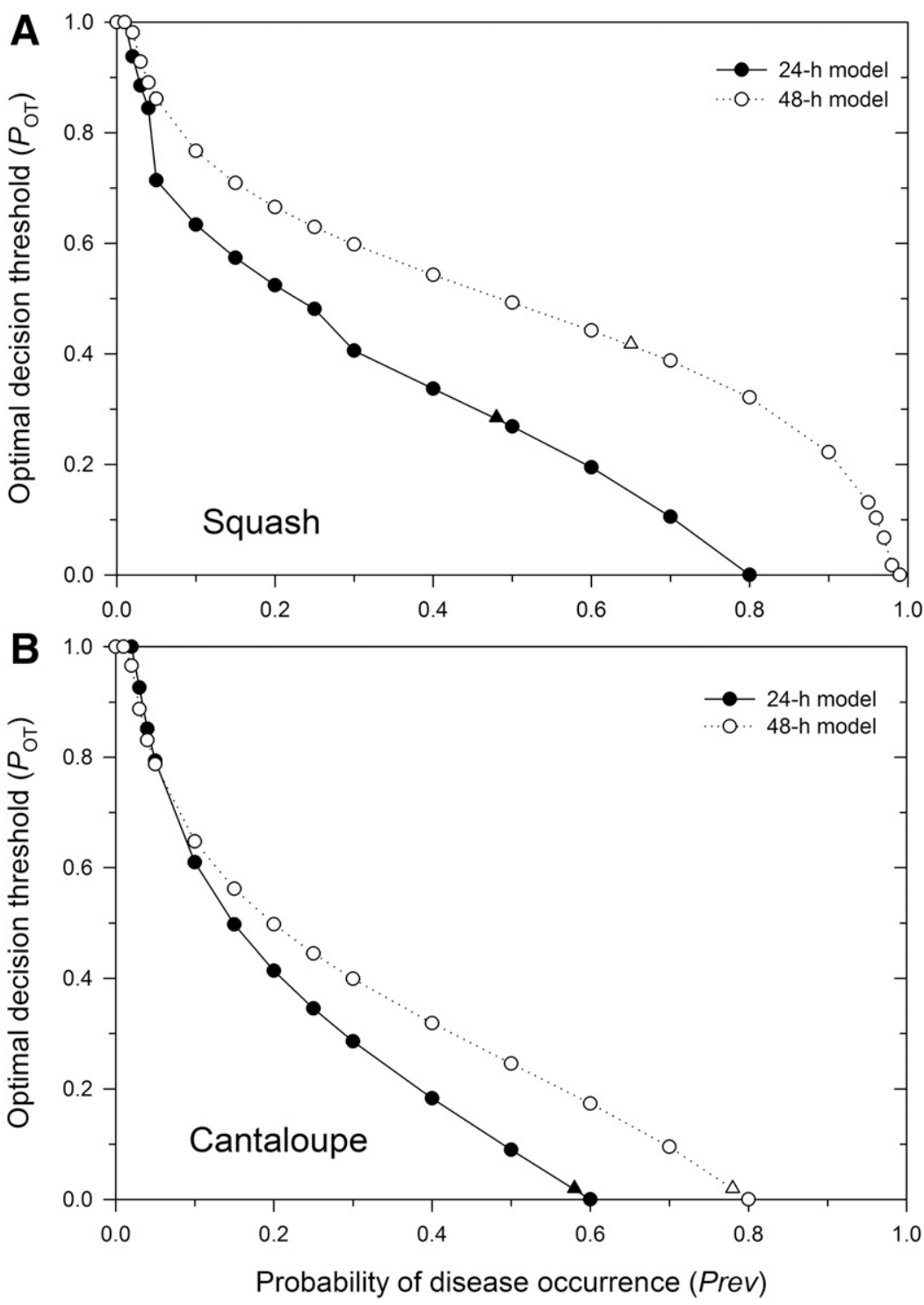

Fig. 4. Optimum decision threshold $\left(P_{\mathrm{OT}}\right)$ as a function of the probability of disease occurrence on $\mathbf{A}$, squash and $\mathbf{B}$, cantaloupe for 24- and 48-h models based on an economic assumption of $30 \%$ end-of-season crop loss and two and four fungicide treatments against Pseudoperonospora cubensis for cantaloupe and squash, respectively. Solid or open circles represent select action thresholds or cutoff points that can be used to classify observations, while solid and open triangles are thresholds for actual levels of disease prevalence observed during the experimental period. 
fungicide spray (Ojiambo et al. 2011). Subsequent sprays could then be recommended using the 24-h model based on the favorability of the prevailing weather conditions in the area of interest. Meteorological data on RH and temperature for specific areas can obtained from the nearest local weather stations and algorithms can be developed to automatically calculate dT and RH80. The risk of disease development can then be determined using the 24-h model to determine whether a spray is needed. Although the CDM ipmPIPE forecasting system has improved management of CDM in the eastern United States (Ojiambo et al. 2011) by timing the first spray, most of the fungicide applications during the season and the more costly fungicides are used after initial infection (Holmes et al. 2015). Thus, models for predicting the daily infection risk of cucurbits by $P$. cubensis have the potential to further reduce the amount of fungicide or the cost associated with fungicides applied to cucurbit crops during the growing season.

\section{Acknowledgments}

We thank L. K. Mehra for his assistance with some preliminary data analysis.

\section{Literature Cited}

Allouche, O., Tsoar, A., and Kadmon, R. 2006. Assessing the accuracy of species distribution models: Prevalence, kappa and the true skill statistic (TSS). J. Appl. Ecol. 43:1223-1232.

Arauz, L. F., Neufeld, K. N., Lloyd, A. L., and Ojiambo, P. S. 2010. Quantitative models for germination and infection of Pseudoperonospora cubensis in response to temperature and duration of leaf wetness. Phytopathology 100:959-967.

Cohen, Y. 1977. The combined effects of temperature, leaf wetness, and inoculum concentration on infection of cucumbers with Pseudoperonospora cubensis. Can. J. Bot. 55:1478-1487.

Cohen, Y., and Rotem, J. 1969. The effects of lesion development, air temperature, and duration of moist period on sporulation of Pseudoperonospora cubensis in cucumbers. Isr. J. Bot. 18:135-140.

Everts, K. L., and Newark, M. J. 2013. Evaluation of organic fungicides for management of mildew diseases of cucurbits, 2013. Plant Dis. Manage. Rep. 8:V210.

Fabre, F., Dedryver, C. A., Leterrier, J. L., and Plantegenest, M. 2003. Aphid abundance on cereals in autumn predicts yield losses caused by Barley yellow dwarf virus. Phytopathology 93:1217-1222.

Fabre, F., Plantegenest, M., and Yuen, J. 2007. Financial benefit of using crop protection decision rules over systemic spraying strategies. Phytopathology 97:1484-1490.

Fan, X., Zhang, S., and Fu, Y. 2014. Field evaluation of experimental and commercial fungicides to control downy mildew in squash, 2014. Plant Dis. Manage. Rep. 9:V050.

Ferreira, W. 2016. Enterprise Budgets: Watermelons-on plastic-drip irrigationseedless. Online publication. Clemson Cooperative Extension, Clemson, SC. www.clemson.edu/extension/agribusiness/files/enterprise-budgets/watermelonsplasticirr.pdf

Gent, D. H., Mahaffee, W. F., McRoberts, N., and Pfender, W. F. 2013. The use and role of predictive systems in disease management. Annu. Rev. Phytopathol. 51:267-289.

Gent, D. H., and Ocamb, C. M. 2009. Predicting infection risk of hop by Pseudoperonospora humuli. Phytopathology 99:1190-1198.

Gent, D. H., and Turechek, W. W. 2015. Identifying optimal action thresholds for disease predictors by receiver operating characteristic curve analysis. Pages 251-257 in: Exercises in Plant Disease Epidemiology, 2nd ed. K. L. Stevenson and M. J. Jeger, eds. American Phytopathological Society, St. Paul, MN

Granke, L. L., Morrice, J. J., and Hausbeck, M. K. 2014. Relationships between airborne Pseudoperonospora cubensis sporangia, environmental conditions, and cucumber downy mildew severity. Plant Dis. 98:674-681.

Hausbeck, M. K. 2017. Downy mildew. Pages 56-59 in: Compendium of Cucurbit Diseases. A. P. Keinath, W. M. Wintermantel, and T. A. Zitter, eds. American Phytopathological Society, St. Paul, MN

Hoagland, D. R., and Arnon, D. I. 1950. The water culture method for growing plants without soil. Calif. Agric. Exp. Stn. Circ. 347:1-23.

Holmes, G. J., Ojiambo, P. S., Hausbeck, M. K., Quesada-Ocampo, L., and Keinath, A. P. 2015. Resurgence of cucurbit downy mildew in the United States: A watershed event for research and extension. Plant Dis. 99: 428-441.
Kanetis, L., Holmes, G. J., and Ojiambo, P. S. 2010. Survival of Pseudoperonospora cubensis sporangia exposed to solar radiation. Plant Pathol. 59:313-323.

Keinath, A. P., Dubose, C. D., Conrad, C. D., and Rushton, M. D. 2014. Evaluation of Zampro and SP2700 for control of downy mildew on zucchini, 2014. Plant Dis. Manage. Rep. 9:V075.

Lebeda, A., and Cohen, Y. 2011. Cucurbit downy mildew (Pseudoperonospora cubensis) - biology, ecology, epidemiology, host-pathogen interaction and control. Eur. J. Plant Pathol. 129:157-192.

Lebeda, A., and Widrlechner, M. P. 2003. A set of Cucurbitaceae taxa for differentiation of Pseudoperonospora cubensis pathotypes. J. Plant Dis. Prot. 110:337-349.

Madden, L. V., Hughes, G., and van den Bosch, F. 2007. The Study of Plant Disease Epidemics. American Phytopathological Society, St. Paul, MN.

Metz, C. E. 1978. Basic principles of ROC analysis. Semin. Nucl. Med. 8:283-298.

Monserud, R., and Leemans, R. 1992. Comparing global vegetation maps with the Kappa statistic. Ecol. Modell. 62:275-293.

NASS. 2012. Quick Stats. Online publication. United States Department of Agriculture-National Agricultural Statistics Service (NASS) Interactive Online Statistical Database. https://quickstats.nass.usda.gov/

Neufeld, K. N., Isard, S. A., and Ojiambo, P. S. 2013. Relationship between disease severity and escape of Pseudoperonospora cubensis sporangia from a cucumber canopy during downy mildew epidemics. Plant Pathol. 62: $1366-1377$.

Neufeld, K. N., Keinath, A. P., and Ojiambo, P. S. 2017. A model to predict the risk of infection of cucumber by Pseudoperonospora cubensis. Microb. Risk Anal. 6:21-30.

Neufeld, K. N., and Ojiambo, P. S. 2012. Interactive effects of temperature and leaf wetness duration on sporangia germination and infection of cucurbit hosts by Pseudoperonospora cubensis. Plant Dis. 96:345-353.

Ojiambo, P. S., Gent, D. H., Quesada-Ocampo, L. M., Hausbeck, M. K., and Holmes, G. J. 2015. Epidemiology and population biology of Pseudoperonospora cubensis: A model system for management of downy mildews. Annu. Rev. Phytopathol. 53:223-246.

Ojiambo, P. S., and Holmes, G. J. 2011. Spatio-temporal spread of cucurbit downy mildew in the eastern United States. Phytopathology 101:451-461.

Ojiambo, P. S., Holmes, G. J., Britton, W., Keever, T., Adams, M. L., Babadoost, M., Bost, S. C., Boyles, R., Brooks, M., Damicone, J., Draper, M. A., Egel, D. S., Everts, K. L., Ferrin, D. M., Gevens, A. J., Gugino, B. K., Hausbeck, M. K., Ingram, D. M., Isakeit, T., Keinath, A. P., Koike, S T., Langston, D., McGrath, M. T., Miller, S. A., Mulrooney, R., Rideout, S., Roddy, E., Seebold, K. W., Sikora, E. J., Thornton, A., Wick, R. L., Wyenandt, C. A., and Zhang, S. 2011. Cucurbit downy mildew ipmPIPE: A next generation web-based interactive tool for disease management and extension outreach. Plant Health Prog. Online publication. doi.org/10.1094/ PHP-2011-0411-01-RV

Ojiambo, P. S., and Kang, E. L. 2013. Modeling spatial frailties in survival analysis of cucurbit downy mildew epidemics. Phytopathology 103:216-227.

Palti, J., and Cohen, Y. 1980. Downy mildew of cucurbits (Pseudoperonospora cubensis): The fungus and its hosts, distribution, epidemiology and control. Phytoparasitica 8:109-147.

Pimentel, D., Acquay, H., Biltonen, M., Rice, P., Silva, M., Nelson, J., Lipner, V. Giordano, S., Horowitz, A., and D'Amore, M. 1992. Environmental and economic costs of pesticide use. Bioscience 42:750-760.

Rideout, S. L., Waldenmaier, C. M., Mahovic, M. J., and Custis, J. T., Jr. 2007. Evaluation of fungicides for the control of downy mildew in cantaloupe, 2007. Plant Dis. Manage. Rep. 2:V097.

Rowlandson, T., Gleason, M., Sentelhas, P., Gillespie, T., Thomas, C., and Hornbuckle, B. 2015. Reconsidering leaf wetness duration determination for plant disease management. Plant Dis. 99:310-319.

Royle, D. J. 1973. Quantitative relationships between infection by the hop downy mildew pathogen, Pseudoperonospora humuli, and weather and inoculum factors. Ann. Appl. Biol. 73:19-30.

Sentelhas, P. C., Dalla Marta, A., Orlandini, S., Santos, E. A., Gillespie, T. J., and Gleason, M. L. 2008. Suitability of relative humidity as an estimator of leaf wetness duration. Agric. For. Meteorol. 148:392-400.

Thomas, A., Carbone, I., Cohen, Y., and Ojiambo, P. S. 2017. Occurrence and distribution of mating types of Pseudoperonospora cubensis in the United States. Phytopathology 107:313-321.

Turechek, W. W., and Wilcox, W. F. 2005. Evaluating predictors of apple scab with receiver operating characteristic curve analysis. Phytopathology 95: 679-691 